08

\title{
Влияние наноразмерных форм углерода на свойства и восприимчивость к импульсному пучку электронов энергонасыщенной соли кобальта
}

\author{
(C) Г.Г. Савенков, ${ }^{1,3}$ В.А. Морозов, ${ }^{2}$ М.А. Илюшин, ${ }^{3}$ И.А. Оськин, ${ }^{1}$ В.А. Брагин, ${ }^{1}$ А.С. Козлов ${ }^{3}$ \\ ${ }^{1}$ Научно-производственное объединение „Поиск“, \\ 188662 Мурино, Ленинградская обл., Россия \\ ${ }^{2}$ Санкт-Петербургский государственный университет, \\ 199034 Санкт-Петербург, Россия \\ ${ }^{3}$ Санкт-Петербургский государственный технологический институт (Технический университет), \\ 190013 Санкт-Петербург, Россия \\ e-mail: sav-georgij@yandex.ru
}

(Поступило в Редакцию 2 марта 2017 г.)

Представлены результаты исследований по влиянию фуллеренов и детонационных наноалмазов на процесс инициирования комплексного перхлората кобальта импульсным пучком электронов наносекундной длительности. Приведены результаты термической совместимости экспериментальных композиций в неизотермических условиях.

DOI: 10.21883/JTF.2017.11.45133.2227

\section{Введение}

В настоящее время интерес достаточно большого количества групп исследователей привлекает возможное практическое применение наноразмерных форм углерода (НФУ) (фуллеритов и детонационных наноалмазов) в различных отраслях промышленности - электронике, химической (нефтехимической), фармацевтической, металлургической и др.

Фуллериты - системы, состоящие из молекул фуллеренов, имеют размеры в десятки нанометров и являются типичными полупроводниками [1]. Детонационные наноалмазы (ДНА) имеют кристаллическую решетку, которая относится к кубической сингонии, их поверхность покрыта углеродсодержащей (графеновой) оболочкой, состоящей в основном из углеродных атомов в состоянии $s p^{2}$-гибридизации, что определяет необычные свойства композиционных материалов при взаимодействии ДНА с частицами других веществ [2]. Фуллериты, являясь полупроводниками, легко эмитируют свободные электроны при нагревании, а ДНА представляют собой полирадикалы, которые катализируют цепные процессы при горении энергонасыщенных составов.

Применение указанных форм углерода в качестве гипотетических добавок в энергонасыщенные вещества (ЭНВ) или материалы (ЭНМ) (по крайней мере, в относящиеся к взрывчатым веществам и составам), которые могут повысить те или иные эксплуатационные характеристики ЭНВ (ЭНМ), пока носит единичный характер. Например, есть сведения, что добавки структурированных частиц углерода (графена) размером 200-500 nm в ракетное топливо (нитрометан) увеличивают скорость его горения в 2.75 раза [3]. Такая эффективность, по мнению авторов, достигается за счет высокой теплопро- водности и излучательных свойств графена, а также его способности к полному сгоранию.

Добавление в этилированное автомобильное топливо углеродных нанотрубок также повышает его эффективность, по крайней мере, в части улучшения характеристик воспламеняемости [4].

В целом же положение с применением рассматриваемых в настоящей работе НФУ связано с их недостаточной доступностью, а также с их относительно высокой стоимостью. Тем не менее, в перспективе, с ростом доступности и снижением стоимости НФУ их использование в качестве добавок в энергонасыщенные материалы вполне допустимо и возможно.

Можно предположить, что такие добавки будут перспективны для ЭНМ, инициирование которых будет связано с электрофизическими воздействиями (электрическим разрядом или действием импульсного электронного пучка), поскольку наноразмерные полупроводящие и проводящие добавки приводили к достаточно интересным результатам при воздействии пучка на ЭНМ $[5,6]$. В качестве добавок в указанных работах использовались порошки окиси меди или чистой меди со средним размером частиц 30-70 nm. Порошки являлись добавками в энергонасыщенный состав на основе пикрата калия. В работе [7] было показано сенсибилизирующее влияние коллоидного графита и алмазного порошка на ТЭН, не связанное с образованием дополнительных концентраторов механического напряжения и определяемое только электрофизическими свойствами добавки.

Цель настоящей работы состояла в определении влияния добавок НФУ (фуллеритов и детонационных наноалмазов) на свойства энергонасыщенного соединения солей кобальта и восприимчивости ее композиций c НФУ к высокоэнергетичному электронному пучку (ВЭП) наносекундной длительности. 


\section{Энергонасыщенный материал, НФУ, экспериментальные методики}

В качестве энергонасыщенного материала был взят амминат кобальта: перхлорат (5-нитротетразолато-N ${ }^{2}$ ) пентааминкобальта (III) с акцепторным заместителем (соединение NCP), имеющий выраженный участок перехода горения в детонацию [8]. Ранее указанный ЭНМ был рекомендован в качестве взрывчатого вещества для безопасного низковольтного детонатора, кроме того, NCP относится к перспективным светочувствительным энергонасыщенным веществам [9].

Плотность кристаллов NCP $\rho_{\exp }=2.03 \mathrm{~g} / \mathrm{cm}^{3}$, скорость детонации $V_{(\rho \exp )}=6.65 \quad(1.61) \mathrm{km} / \mathrm{s}$, температура вспышки $T_{i g n}=320^{\circ} \mathrm{C}$, температура разложения $T_{d e c}=265^{\circ} \mathrm{C}$, определены методом DTA/TG. Минимальный заряд NCP по гексогену в оболочке капсюлядетонатора № 8 составляет около $0.2 \mathrm{~g}$. Участок перехода горения в детонацию у $\mathrm{NCP}$ в диаметре $6.25 \mathrm{~mm}$ при $\rho_{\text {ехр }}=1.60-1.63 \mathrm{~g} / \mathrm{cm}^{3}$ составляет $\sim 4.5 \mathrm{~mm}$.

По чувствительности к удару NCP находится между тетранитратом пентаэритрита (ТЭН) и 1,3,5-тринитро1,3,5-триазациклогексаном (гексогеном).

Соединение NCP обладает пониженной чувствительностью к разрядам статического электричества (по сравнению с традиционными инициирующими взрывчатыми веществами (ИВВ)). Удельное объемное электрическое сопротивление $10^{12}-10^{13} \Omega \cdot \mathrm{m}$.

Продукт негигроскопичен. Термостатирование NCP в герметичных условиях при $200^{\circ} \mathrm{C}$ в течение $6 \mathrm{~h}$ не приводит к изменению его свойств. Соединение NCP малотоксично [10].

В качестве наноразмерных углеродных добавок были выбраны фуллериты (средний размер $30-50 \mathrm{~nm}$ ), состоящие из наиболее распространенного фуллерена $\mathrm{C}_{60}$, и детонационные наноалмазы размером менее $100 \mathrm{~nm}$.

Энергонасыщенные композиции получали следующим образом: смешение NCP с $C_{60}$ вели в толуоле. Потом растворитель испаряли при комнатной температуре. И поскольку средний размер частиц $\mathrm{NCP}$, несмотря на его высокую полидисперсность, лежит в диапазоне $10-20 \mu \mathrm{m}$, на поверхности частиц комплекса аммината кобальта оседали частицы $\mathrm{C}_{60}$. Так как толуол мог частично растворить фуллерены, после испарения взвешиванием контролировали массу полученной композиции, с высокой степенью точности ее масса всегда совпадала с суммой масс исходных компонентов.

Смешение NCP с ДНА вели в пропаноле-2, который хорошо смачивал поверхности компонентов (они оба гидрофильные вещества) и позволял хорошо перемешать состав. Растворитель испаряли при комнатной температуре. Для удаления остатков растворителей смеси термостатировали при $60-80^{\circ} \mathrm{C}$ в течение $30 \mathrm{~min}$. Затем аналогично предыдущей композиции $\left(\mathrm{NCP}+\mathrm{C}_{60}\right)$ проверяли массу полученной композиции и сравнивали с суммой масс исходных компонентов. Во всех случаях масса композиции совпадала с суммарной массой.

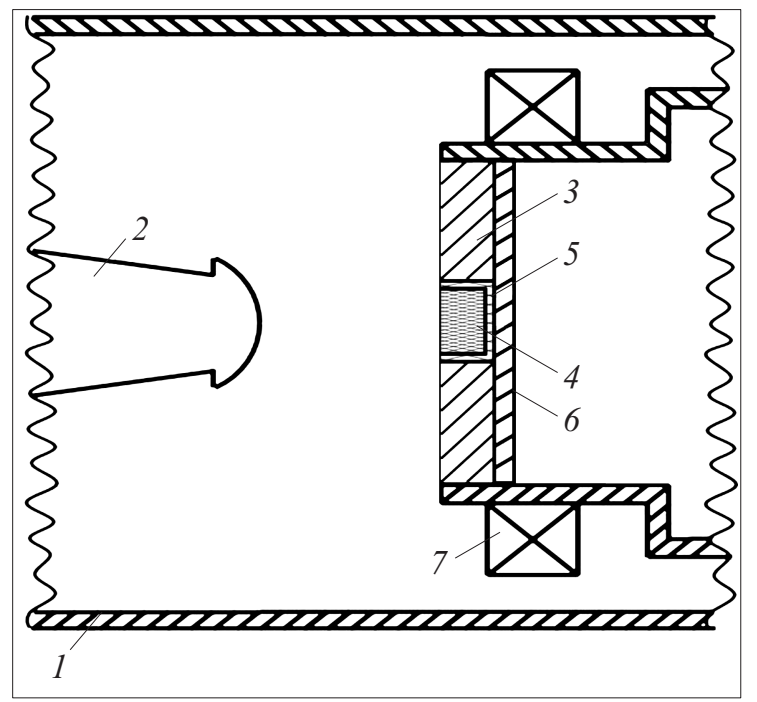

Рис. 1. Экспериментальная схема облучения пучком электронов образца: 1 - вакуумная камера, $2-$ катод, $3-$ стальное кольцо, 4 - энергонасыщенная композиция, 5 - колпачок, 6 - подложка, 7 - пояс Роговского (измеритель тока).

Энергонасыщенная композиция (состав) помещалась в латунный колпачок высотой $3 \mathrm{~mm}$ и внутренним диаметром $4.5 \mathrm{~mm}$. Внешний диаметр стального кольца, в которое устанавливался колпачок с составом, $-30 \mathrm{~mm}$. Стальное кольцо устанавливалось на стальную подложку толщиной $2.2-2.5 \mathrm{~mm}$. Схема облучения образца (ЭНМ) пучком в принципе аналогична схеме, приведенной в работах $[4,5,10]$ (рис. 1). В качестве электронного ускорителя использовалась установка ГКВИ-300 [11]. Эксперименты проводились как с отсечкой (путем установки на кольцо алюминиевой фольги толщиной $20 \mu \mathrm{m}$ ) катодного факела (КФ) (т.е. в этом случае на образец действовал только электронный пучок), так и без отсечки (в этом случае на образец действовал ВЭП + КФ). КФ - взрыв микронеоднородностей на катоде из-за лавинообразного нарастания тока, вызванного джоулевым нагревом эмиттера [12]. КФ генерируется с катода вслед за электронным пучком и имеет скорость $120-150 \mathrm{~km} / \mathrm{s}[13,14]$. Катодный факел обладает большей плотностью по сравнению с ВЭП и имеет высокую температуру $(\sim 2500-3500 \mathrm{~K})$, поэтому если для возбуждения взрывчатых превращений (ВП) (горения или детонации) энергонасыщенных материалов (ЭНМ) энергии пучка не хватает, то добавочная энергия за счет КФ может привести к инициированию ВП $[5,11,15]$.

Плотность запрессовки композиции (состава) находилась в диапазоне $1.0-1.9 \mathrm{~g} / \mathrm{cm}^{3}$. Высокий разброс плотности объясняется желанием исследования влияния плотности на восприимчивость к действию ВЭП. Это обусловлено двумя причинами. Во-первых, увеличение плотности ЭНМ приводит к увеличению его энергетических характеристик и одновременному снижению чувствительности к внешним воздействиям. Особенно (и это вторая причина) с увеличением плотности должна 
резко уменьшаться чувствительность к действию ВЭП. Такое уменьшение чувствительности объясняется тем, что глубина максимального энерговыделения пучка, а также экстраполированная глубина пробега электронов зависит от плотности вещества [11]. А именно чем выше плотность, тем ниже значения глубин максимального энерговыделения и пробега электронов. В то же время выделение энергии электронного пучка происходит практически на каждой молекуле вещества, нагрев которых до критической температуры и приводит к быстрой экзотермической реакции (взрывчатому превращению). Таким образом, чем глубже проникнут электроны пучка, тем выше будет вероятность возбуждения взрывчатых превращений, т. е. при малых значениях плотности заряда вероятность возбуждения ВП резко возрастает.

Массовое содержание фуллеритов и ДНА в композициях варьировалось от 10 до 25\% с шагом 5\%. Для уточнения обнаруженного эффекта (о котором речь пойдет ниже) были проведены эксперименты с 18- и 22\%-ным содержанием фуллеритов.

Длительность импульса тока на его полувысоте составляла 20-40 ns, средняя энергия электронов в пучке - $250 \mathrm{keV}$, расстояние между катодом и образцом $4 \mathrm{~mm}$, диаметр пучка $-8 \mathrm{~mm}$. Осциллограммы тока (1) и напряжения (2) при действии электронного пучка на

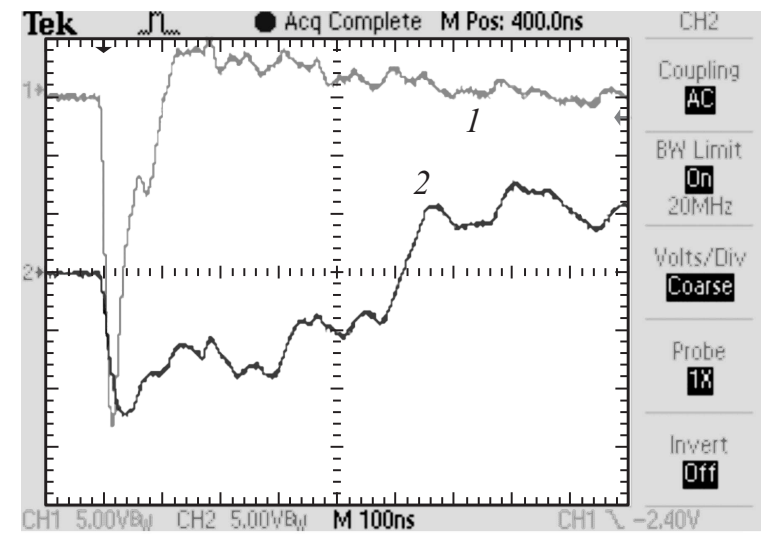

$a$

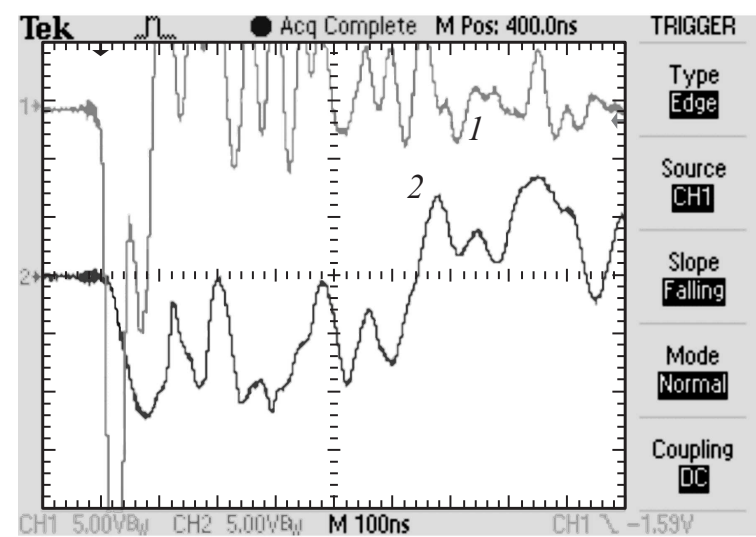

Рис. 2. Осциллограммы тока (1) и напряжения (2) при генерировании импульсного электронного пучка на образец NCP $(a)$ и на композицию с 10\%-ным содержанием фуллеренов $(b)$.

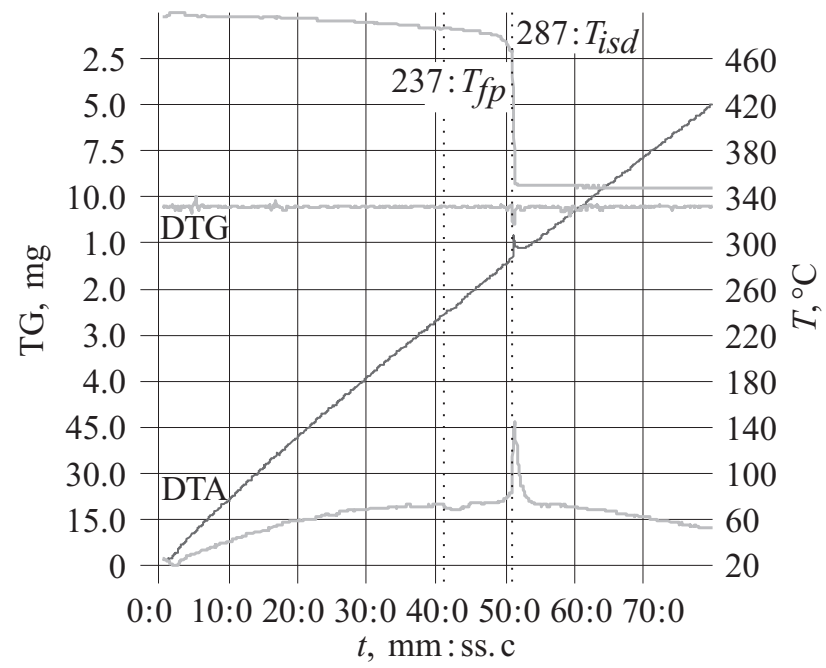

Рис. 3. Типичная дериватограмма образца состава $85 \%$ $\mathrm{NCP}+15 \%$ фуллерена $\mathrm{C}_{60}$.

образец с чистым энергонасыщенным составом (NCP) приведены на рис. 2, a, при действии на композицию с 10\%-ным содержанием фуллеренов - на рис. 2, $b$ (цифры 1 и 2 указывают номера кривых на осциллограммах).

Термическая совместимость образца NCP с наноуглеродными добавками в неизотермических условиях была определена методом TG/DTA на дериватографе „Паулик Эрдеи“ (Венгрия) (модернизированный). Тип держателя образца - кварцевый тигель с внутренней выемкой под термопару (диаметр $8 \mathrm{~mm}$, высота $12 \mathrm{~mm}$ ), тип термопары - платино-платинородиевая (содержание родия $10 \%$ ), среда испытания - воздух, без прокачки.

Скорость нагрева $5^{\circ} \mathrm{C} / \mathrm{min}$, интервал температур $20-500^{\circ}$ C. Вид типичной дериватограммы представлен на рис. 3.

\section{Результаты экспериментов и их обсуждение}

\section{Действие ВЭП на энергонасыщенные композиции с фуллеритами}

Отсечка катодного факела во всех случаях приводила к отрицательному результату (т.е. взрывчатые превращения в образцах при действии ВЭП не осуществлялись и видимых изменений в них не наблюдалось). Эксперименты с отсечкой проводились как на чистом соединении NCP, так и на композициях с 10- и 15\%-ным содержанием фуллеритов, на композиции с содержанием 18, 20, 22 и 25\% фуллеритов действовал уже только комплекс ВЭП + КФ. При действии ВЭП + КФ в образцах во всех случаях происходили взрывчатые превращения, что фиксировалось по отсутствию соединения NCP или композиции $\mathrm{NCP}+\mathrm{C}_{60}$ в колпачке, термическим пятнам на катоде и кольце. Кроме того, фиксировалась глубина 


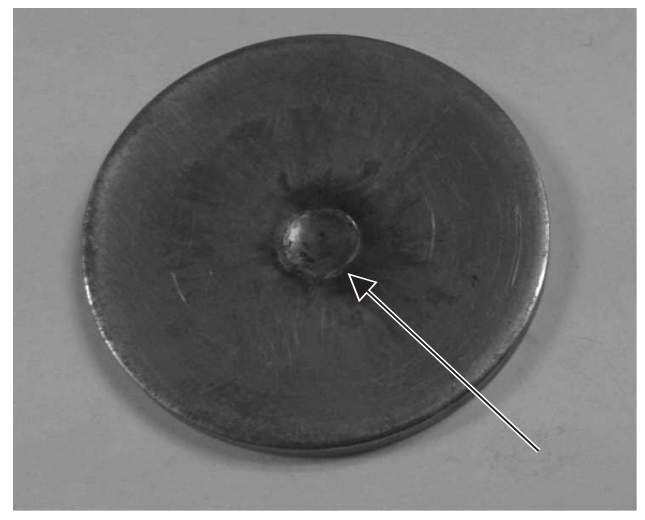

Pис. 4. Отпечаток (указан стрелкой) на стальной пластине.

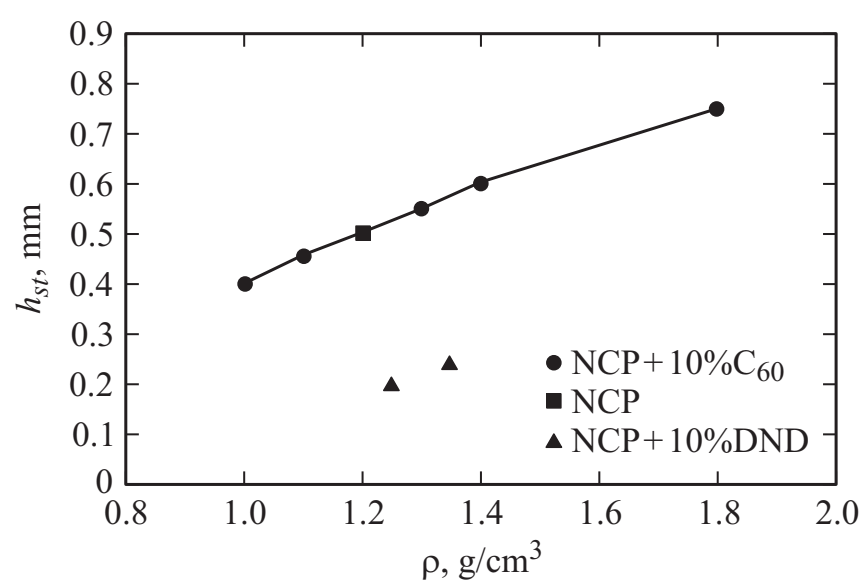

Рис. 5. Зависимость глубины отпечатка от плотности взрывчатой композиции.

отпечатка колпачка 5 на стальной подложке 6 (номера позиций относятся к рис. 1) (рис. 4).

Зависимость глубины отпечатка от плотности запрессованной композиции при $10 \%$-ном содержании $\mathrm{C}_{60}$ приведена на рис. 5. Как видно из данных, приведенных на рисунке, с увеличением плотности глубина отпечатка растет и, наконец, при плотности $\rho_{\exp }=1.86 \mathrm{~g} / \mathrm{cm}^{3}$ подложка разбивалась на 6-7 крупных фрагментов и множество мелких.

После того как были проведены опыты с чистым соединением $\mathrm{NCP}$ и с композицией $\left(10 \% \mathrm{C}_{60}\right)$, было обращено внимание на то, что добавка фуллеренов приводит к большему энергетическому эффекту от срабатывания составов. Термическое пятно на кольце было по размеру много больше, так же как и вмятина от латунного колпачка на стальной подложке при плотности $\rho_{\exp }=1.375 \mathrm{~g} / \mathrm{cm}^{3}$ под кольцом была на $0.1-0.15 \mathrm{~mm}$ глубже (максимальная глубина вмятины по центру составляла $0.7 \mathrm{~mm})$.

Данная тенденция продолжалась и в случае композиций с $15-$ и $20 \%$-ным содержанием фуллеренов. Например, когда вместо стальной подложки устанавливались свинцовые толщиной $1.75 \mathrm{~mm}$, то колпачок с $20 \%$-ным содержанием фуллеренов пробивал две свинцовые подложки, а с $15 \%$-ным содержанием - одну, с 10\%-ным содержанием колпачок хоть и пробивал свинцовую подложку, но застревал в ней. Максимальная глубина вмятины в стальной подложке при $20 \%$-ном содержании фуллерена-60 составляла $0.8 \mathrm{~mm}$. При $25 \%$-ном содержании фуллеренов энергетика состава резко падала: вмятина от колпачка на стальной подложке была едва заметна, термическое пятно на кольце было идентично по размеру пятну на кольце. Можно предполагать, что параметры режима взрывчатого превращения в композиции с 20\%-ным содержанием фуллеритов (так же как и с $10 \%$-ным содержанием при максимальной плотности) были существенно выше, а сами режимы относились либо к быстрому горению, либо к низкоскоростной детонации. В случае возникновения режима низкоскоростной детонации можно полагать, что резко снизилась вышеприведенная длина участка перехода горения в детонацию.

Поэтому с целью установления оптимального процентного содержания фуллеренов были изготовлены образцы с $18 \%$ - и $22 \%$-ным содержанием фуллеренов (плотность запрессовки $1.375 \mathrm{~g} / \mathrm{cm}^{3}$ ). Были получены следующие результаты: и при $18 \%$, и при $22 \%$ содержания $\mathrm{C}_{60}$ вмятины на стальной подложке по глубине практически соответствовали образцам с $15 \%$-ным содержанием фуллеренов и были меньше, чем у образцов с 20\%-ным содержанием. Таким образом, можно констатировать, что $20 \%$ массовой доли фуллеренов в энергонасыщенном соединении кобальтовой соли (NCP) является оптимальным с точки зрения достижения композицией $\mathrm{NCP}+\mathrm{C}_{60}$ наибольших энергетических характеристик. В данном случае речь может идти о таких характеристиках, как удельная теплота взрывчатого превращения и связанная с ней температура продуктов взрывчатого превращения композиции, а также давление на фронте взрывчатого превращения. Эти характеристики и обусловили увеличение глубины отпечатка.

С чем же может быть связано повышение теплоты взрывчатого превращения и температуры его продуктов? Как известно, теплота взрывчатого превращения определяется (в соответствии с законом Гесса [16]) разностью между теплотой образования продуктов взрыва (горения) и теплотой образования энергонасыщенной композиции (для нашего случая) из элементов, ее составляющих. Тогда, вероятно, вследствие своей высокой реакционной способности (гипотетической - в нашем случае) фуллерен-60 может вступать в самые различные (быть может - невероятные) соединения с элементами $\mathrm{NCP}$, образуя большое количество продуктов взрывчатого превращения, повышая тем самым их суммарную теплоту. Как следствие этого повышения, возрастают теплота взрывчатого превращения и его температура. Экстремум в $20 \%$ массового содержания $\mathrm{C}_{60}$ подлежит дальнейшему изучению. Каталитичность этой добавки 
с точки зрения увеличения скорости горения (взрывчатого превращения) также требует дополнительных исследований.

\section{Действие ВЭП на энергонасыщенные композиции с ДНА}

Отсечка катодного факела так же, как и в случае действия ВЭП на композицию $\mathrm{NCP}+\mathrm{C}_{60}$, не приводила к взрывчатым превращениям в композициях с 10и 15\%-ным содержанием ДНА, поэтому на композиции с 20- и 25\%-ным содержанием ДНА воздействовали комплексом ВЭП + КФ. В этом случае во всех вышеперечисленных композициях $\mathrm{NCP}+$ ДНА (включая с содержанием 10 и 15\% ДНА) происходили быстрые экзотермические реакции. Фиксация таких реакций осуществлялась аналогично фиксации взрывчатых превращений в композициях $\mathrm{NCP}+\mathrm{C}_{60}$.

Однако уже при 10\%-ном содержании ДНА было заметно, что энергетика быстрых реакций существенно ниже, чем в случае композиций с 10\%-ным содержанием фуллеритов, поскольку глубина отпечатков колпачков с композициями с ДНА на стальной подложке была в 2.5 раза меньше, чем у колпачков с композициями с фуллеритами (рис. 4).

Дальнейшее увеличение в композициях процентного содержания детонационных наноалмазов приводило к следующему. При 15- и 20\%-ном содержании ДНА композиции выгорали, но отпечатки были едва заметны. При 25\%-ном содержании композиция сгорала, но отпечатка не было, и, наконец, при 30\%-ном содержании ДНА взрывчатых превращений не происходило, композиция оставалась цела.

Таким образом, можно уверенно полагать, что добавка детонационных наноалмазов снижает энергетические характеристики получаемых энергонасыщенных композиций, и при некотором критическом содержании ДНА в композициях у них пропадает восприимчивость к ВЭП (при используемых параметрах пучка).

\section{Термическая совместимость NCP с НФУ при повышенных температурах}

Экспериментальные результаты по термической совместимости в виде определенных температур начала разложения $T_{s d}$ и начала интенсивного разложения $T_{i s d}$ обобщены в таблице.

Как видно из таблицы, добавление к NCP фуллеренов неоднозначно влияет на термическую стабильность смесей: зависимость обеих температур от процентного содержания $\mathrm{C}_{60}$ имеет явно выраженный колебательный характер. При этом максимальный размах температуры начала разложения почти в 2 раза превосходит аналогичный размах температуры начала интенсивного разложения. При содержании фуллерена $\mathrm{C}_{60}$ в смеси 20\% происходит снижение температуры начала
Совместимость NCP с НФУ

\begin{tabular}{c|c|c}
\hline Компонент & $\begin{array}{c}\text { Масса навески, } \\
\mathrm{mg}\end{array}$ & $\begin{array}{c}T_{s d} / T_{i s d}, \\
{ }^{\circ} \mathrm{C}\end{array}$ \\
\hline $\mathrm{NCP}$ & 54 & $256 / 285$ \\
$\mathrm{NCP}+10 \% \mathrm{C}_{60}$ & 50 & $260 / 280$ \\
$\mathrm{NCP}+15 \% \mathrm{C}_{60}$ & 49 & $252 / 287$ \\
$\mathrm{NCP}+20 \% \mathrm{C}_{60}$ & 41 & $247 / 282$ \\
$\mathrm{NCP}+22 \% \mathrm{C}_{60}$ & 44 & $269 / 284$ \\
NCP $+25 \% \mathrm{C}_{60}$ & 45 & $257 / 281$ \\
NCP $+10 \%$ ДНА & 43 & $260 / 280$ \\
NCP $+15 \%$ ДНА & 44 & $261 / 284$ \\
NCP $+20 \%$ ДНА & 39 & $265 / 284$ \\
NCP $+25 \%$ ДНА & 46 & $269 / 282$ \\
NCP $+30 \%$ ДНА & 49 & $246 / 286$ \\
\end{tabular}

разложения $T_{s d}$ смеси по сравнению с исходным (без добавок) состоянием NCP на $9^{\circ} \mathrm{C}$. Наблюдаемый эффект снижения $T_{s d}$, как и то, что при этой концентрации наблюдается максимальный энергетический эффект при взрывчатом превращении под воздействием ВЭП + КФ, может быть связан с каталитическими свойствами фуллеренов в реакциях разложения комплекса. Повышение термической стабильности смесей при концентрации фуллеренов 22-25\%, по-видимому, обусловлено тем, что наноразмерные добавки, входящие в исследуемые композиции, начинают эффективнее перераспределять тепло, образующееся в результате первичной реакции разложения, и его общий отток во внешнюю среду замедляется.

В смесях NCP с наноалмазами при увеличении процентного содержания последних $T_{s d}$ монотонно увеличивается, при этом изменение $T_{s i d}$ незначительно. И только для смеси $70 \% \mathrm{NCP} / 30 \%$ ДНА происходит достаточно резкое уменьшение (на $10^{\circ} \mathrm{C}$ по отношению к $\mathrm{NCP}$ и на $13^{\circ} \mathrm{C}$ по отношению к предыдущему (25\%) содержанию ДНА). Можно предложить следующее вероятное объяснение данного факта. Термическое разложение структуры вещества представляет собой сложный процесс, состоящий из физических и химических превращений. Тогда резкое снижение термической стабильности смеси 70\%NCP/30\% ДНА может быть связано с тем, что при указанном соотношении компонентов произошел некий физический (тепловой, фазовый, электрический и др.) перколяционный переход, и композиция приобрела качественно другие химические и физические, в том числе тепловые, свойства $[17,18]$. Именно этим может быть объяснено отсутствие взрывчатых превращений при действии на композицию $70 \% \mathrm{NCP} / 30 \%$ ДНА ВЭП + КФ с энергетическими параметрами, обеспечиваемыми ГКВИ-300.

В целом можно отметить, что оба типа наноразмерных углеродных добавок оказывают незначительное воздействие на термическую стабильность энергонасыщенных композиций по сравнению с чистым (без добавок) NCP. 


\section{Заключение}

В результате проведенных исследований установлено.

1. Добавка в NCP (перхлорат (5-тринитрометилтетразолато- $\mathrm{N}^{2}$ ) пентааминкобальта (III)) до $25 \%$ массовой доли наноразмерных форм углерода (фуллерена $\mathrm{C}_{60}$ и детонационных наноалмазов) не снижает чувствительности получаемых энергонасыщенных композиций к совокупному воздействию высокоэнергетичного электронного пучка и катодного факела.

2. 30\%-ное содержание ДНА в композиции $\mathrm{NCP}+$ ДНА приводит к полной потере чувствительности к воздействию ВЭП + КФ.

3. $20 \%$-ное содержание $\mathrm{C}_{60}$ в композиции $\mathrm{NCP}+\mathrm{C}_{60}$ приводит к максимальным энергетическим характеристикам энергонасыщенной композиции.

4. Энергетические параметры смесей $\mathrm{NCP}+\mathrm{C}_{60}$ существенно превосходят аналогичные параметры энергонасыщенных композиций $\mathrm{NCP}+$ ДНА.

5. Добавка в NCP наноразмерных форм углерода в целом незначительно влияет на термическую стабильность исследованных энергонасыщенных композиций.

\section{Список литературы}

[1] Kratschmer W., Lamb L.D., Fostiropulos K., Huffman D.R. // Nature. 1990. Vol. 347. P. 354-358.

[2] Байтингер Е.М., Беленков Е.А., Бржезинская М.М., Грешняков В.А. // ФТТ. 2012. Т. 54. Вып. 8. С. 1606-1613.

[3] Sabourin J.L., Dabbs D.M., Yetter R.A. et al. // ACS Nano. 2009. Vol. 3. N 12. P. 3945-3954.

[4] Пенязьков О.Г., Силенков М.А., Шушков С.В. // Инженерно-физический журн. 2013. Т. 86. № 3. С. 503-508.

[5] Савенков Г.Г., Морозов В.А., Брагин В.А. и др. // ЖТФ. 2013. Т. 83. Вып. 7. С. 96-99.

[6] Лукин А.А., Морозов В.А., Рашковский С.А., Савенков Г.Г. // Химическая физика. 2015. Т. 34. № 4. С. 69-75.

[7] Вахидов Р.М., Исхаков Т.Н., Кузнеиов Е.П. и др. // Современные проблемы технической химии. Казань: КГТУ, 2004. C. 447-451.

[8] Илюшин М.А., Целинский И.В. // Российский хим. журн. 2001. T. 45. № 1. С. 72-92.

[9] Тверьянович А.С., Аверьянов М.О., Илюшин М.А. и др. // ЖПХ. 2015. Т. 88. Вып. 2. С. 221-226.

[10] Илюшин М.А., Судариков А.М., Целинский И.В. и др. Металлокомплексы в высокоэнергетических композициях. СПб.: ЛГУ им. А.С. Пушкина, 2010. 114 с.

[11] Морозов В.А., Савенков Г.Г., Брагин В.А. и др. // ЖТФ. 2012. Т. 82. Вып. 5. С. 129-134.

[12] Кариев Г.К., Месяи Г.А., Проскуровский Д.И. и др. // ДАН CССР. 1970. Т. 192. № 2. С. 309-312.

[13] Мещеряков Ю.И., Морозов В.А. // ЖТФ. 1979. Т. 49. Вып. 9. С. 1982-1986.

[14] Morozov V.A., Lukin A.A., Savenkov G.G., Oskin I.A. // 2015 Intern. Conf. on „Stability and Control Processes“ in Memory of V.I. Zubov, SCP 2015 - Proceedings. 30 November 2015, Article number 734084. P. 177-179. 10.1109/SCP. 2015. 7342084.
[15] Савенков Г.Г., Морозов В.А., Лукин А.А. и др. // Письма в ЖТФ. 2014. Т. 40. Вып. 6. С. 50-58.

[16] Андреев К.К., Беляев А.Ф. Теория взрывчатых веществ. М.: Оборонгиз, 1960. $598 \mathrm{c.}$

[17] Рашковский С.А. // ФГВ. 2005. Т. 41. № 1. С. 41-54.

[18] Рашковский С.А., Савенков Г.Г. // ЖТФ. 2013. Т. 83. Вып. 4. C. 47-58. 